\title{
Desenvolvimento de jogos como mecanismo pedagógico: Um relato de experiência na escola pública visando à sustentabilidade e preservação do meio ambiente
}

\author{
Sara das Mercês Silva ${ }^{1}$, Fabíola Pantoja O. Araujo ${ }^{1}$, Saulo W. da Silva Costa ${ }^{2}$, \\ Yomara Pinheiro Pires ${ }^{2}$, Marcos C. da Rocha Seruffo ${ }^{1}$, Josivaldo S. Araujo ${ }^{1}$ \\ ${ }^{1}$ Instituto de Ciências Exatas e Naturais (ICEN) \\ Instituto de Tecnologia (ITEC) Universidade Federal do Para (UFPA) \\ Rua Augusto Correa, 01 - 66075-110 - Belém - PA - Brasil \\ ${ }^{2}$ Campus Castanhal - Universidade Federal do Pará (UFPA) \\ Av. dos Universitarios - 68746-360 - Castanhal- PA - Brasil \\ maru.mercesl8@gmail.com, fpoliveira@ufpa.br, saulo.si.costa@gmail.com, \\ \{yomara, seruffo, josivaldo\}@ufpa.br
}

\begin{abstract}
To awaken in the students of the 5 year the interest for environmental education, was used in this work the development of educational games, approaching the sustainable use of the present river in the municipality of Inhangapi, located in the northeast of Pará. And to evaluate the students' knowledge gain regarding the subjects addressed in class, at the end of the activities the students developed games that involved the subjects taught. The results of the use of game construction contributed to the teaching and learning process in relation to the concepts of Computing and environmental education because almost $60 \%$ of students correctly applied the content taught in game construction.
\end{abstract}

Resumo. Para despertar nos estudantes do $5^{\circ}$ ano o interesse por educação ambiental, utilizou-se neste trabalho o desenvolvimento de jogos educacionais, abordando o uso sustentável do rio presente no município de Inhangapi, localizado no nordeste do Pará. Para avaliar o ganho de conhecimento dos alunos quanto aos assuntos abordados em aula, ao final das atividades os estudantes desenvolveram jogos que envolvessem os temas ensinados. Os resultados mostraram que o uso da construção de jogos contribuiu para o processo de ensino e aprendizagem em relação aos conceitos de Computação e de educação ambiental pois quase $60 \%$ dos alunos aplicaram corretamente o conteúdo ensinado na construção dos jogos.

\section{Introdução}

O ensino da Computação, nos primeiros anos escolares, é um meio de inserir as pessoas, ainda na infância e adolescência no contexto atual das Novas Tecnologias Digitais da informação e Comunicação (NTDICs). [Mittermeir 2013] afirma que, na infância, alunos já compreendem algoritmos, desde que os conceitos sejam ensinados de maneira correta e adequada para a faixa etária dos alunos. Além disso, fala em sua pesquisa que o aprendizado de lógica de programação (no decorrer do texto será usado a sigla "LP", no lugar 
VIII Congresso Brasileiro de Informática na Educação (CBIE 2019)

Anais do XXV Workshop de Informática na Escola (WIE 2019)

do termo "lógica de programação") é interessante e divertido para crianças e desperta nos alunos o interesse em continuar aprendendo. O que evidencia que, a LP pode contribuir para o aprendizado de outros conteúdos, ensinados na escola.

O ensino de algoritmos e pensamento computacional para crianças e adolescentes, já vem sendo aplicados em pesquisas, como em [Garlet et al. 2016, Williams et al. 2015, Farias et al. 2018] O trabalho de [Garlet et al. 2016], aponta a importância do ensino de programação ainda no ensino básico, para preparar os alunos para o ensino superior. Quanto ao uso de jogos, como ferramenta no auxílio ao ensino de algoritmos, [Williams et al. 2015] afirmam que estes ajudam a familiarizar os alunos com fundamentos de algoritmo. [Farias et al. 2018] espõem uma proposta de gamificação da disciplina LP, que aumentou o empenho dos alunos.

Por outro lado [Alves et al. ] afirmam que as mudanças geradas, através do avanço da Computação, vêm refletindo a forma que as pessoas, em especial crianças e jovens, interagem com o mundo, influenciando-os no modo como o conhecimento é construído. É necessário perceber que a inserção de tecnologias no cenário educacional, ocasiona transformações positivas no ensino-aprendizagem, atenuando, também as discrepâncias existentes entre ambientes educacionais distintos [ć2018Integratin].

Em vista disto, os objetivos deste trabalho consistiram na utilização de conceitos básicos de LP, aplicado ao desenvolvimento de jogos educativos, para ensinar conceitos de educação ambiental e sustentabilidade à crianças e adolescentes do município de Inhangapi, localizado em uma região ribeirinha da Amazônia, no nordeste paraense. A partir de dados disponibilizados pelo Sistema de Informações de Indicadores Sociais do Estado do Pará ${ }^{1}$, apenas três escolas da rede municipal de ensino do município, em que desenvolveu-se o trabalho, têm laboratório de informática e computadores, e desses, apenas uma tem acesso à Internet.

Para estimular nos estudantes o interesse por programação e meio ambiente, usouse a ferramenta Scratch ${ }^{2}$ para a construção de jogo educativo utilizado como recurso pedagógico para auxiliar no processo de ensino e aprendizagem dos alunos do $5^{\circ}$ ano do ensino fundamental. Para aproximar os conceitos ensinados a realidade das crianças, $o$ jogo construído abordava o ato de retirar o lixo do rio, presente no município, colocando em pauta temas referentes a educação ambiental.

A escola localiza-se há poucos metros do rio que banha e dá nome ao município. Por se tratar de uma cidade pequena e com pouca infraestrutura, ações como as desenvolvidas neste trabalho, visam também, ajudar no desenvolvimento local. Aliado ao ensino da LP, foram discutidos conceitos socioambientais, pois a construção do jogo tinha como caráter principal contribuir no ensino da educação ambiental e na preservação do rio local. Ao final das aulas, os alunos modificaram o design e lógica do jogo-base, construído em sala, aplicando o conteúdo de algoritmo ensinado em aula. Além dessa atividade, os alunos responderam a um questionário pós-projeto para avaliar se eles conseguiram assimilar todos os conceitos abordados.

Este artigo está estruturado da seguinte forma: na seção 2 são apresentados os trabalhos correlatos, na Seção 3 é descrita a metodologia usada neste trabalho e o deta-

\footnotetext{
${ }^{1} \mathrm{http} / \mathrm{www} 2 . \mathrm{mppa} \cdot \mathrm{mp} . \mathrm{br} / \mathrm{sistemas/gcsubsites/index}$

${ }^{2}$ https://scratch.mit.edu/.
} 
VIII Congresso Brasileiro de Informática na Educação (CBIE 2019)

Anais do XXV Workshop de Informática na Escola (WIE 2019)

lhamento do jogo usado como referência (jogo-base). Na Seção 4 são apresentados os resultados dos questionários estruturados e da atividade avaliativa desenvolvida em sala. Por fim, na Seção 5, são apresentadas as considerações finais deste trabalho.

\section{Trabalhos Correlatos}

Diversas pesquisas e trabalhos que defendem o uso de jogos educacionais como ferramentas pedagógicas que auxiliem no processo de ensino-aprendizagem, o desenvolvimento de jogos e o ensino de conceitos de programação dentro de salas de aulas, vêm sendo desenvolvidos. [Pires et al. 2018, Guerra et al. 2018, Mesquita et al. 2018, Garlet et al. 2016, Williams et al. 2015].

[Pires et al. 2018] desenvolveram um jogo eletrônico educacional com intuito de auxíliar alunos no processo de aprendizagem em ortografia. Os resultados alcançados apontam que o jogo é capaz de ajudar no processo de aprendizagem, chegou-se a esse resultado, com a avaliação do jogo, por 12 usuários. [Guerra et al. 2018] em sua pesquisa destaca o uso de jogos para ajudar no processo de alfabetização de crianças em escolas públicas. Os autores trabalharam realizando testes, com crianças no período de alfabetização, desde 2015, e afirmam que, nesse período, conseguiram ajudar na alfabetização de cerca de 400 crianças.

Em seu trabalho,[Mesquita et al. 2018] apresenta uma plataforma que objetiva permitir aos próprios professores e alunos a opção de desenvolver jogos de uma forma simples, adequando os assuntos dos jogos às finalidades pedagógicas de cada disciplina e professor. Os professores e alunos, utilizaram jogos previamente desenvolvidos e construíram os seus próprios, após isso responderam a um questionário, disponibilizado pelos autores.

Quanto às crianças construírem jogos digitais dentro do ambiente educacional como uma atividade escolar, [Cruz et al. ] relatam uma experiência da criação de jogos em uma escola pública. Os autores afirmam que os alunos conseguiram desenvolver a atividade e se interessaram por desenlvolvimento de jogos. O trabalho de [Garlet et al. 2016] aponta a importância do ensino de lógica de programação ainda no ensino básico, para preparar os alunos para o ensino superior. Quanto ao uso de jogos, como ferramenta no auxílio ao ensino de lógica, [Williams et al. 2015] relata que o seu uso ajudou a familiarizar os alunos com fundamentos de algoritmo.

Existem semelhanças entre os artigos citados e o presente trabalho: o uso e construção de jogos para ajudar em uma disciplina específica e para aproximar as pessoas à Computação. Alguns autores também, utilizaram questionários para avaliar seus resultados, porém neste trabalho, além do questionário, avaliou-se os alunos, através de uma atividade prática de construção de jogos e, além disso, os trabalhos correlatos apresentados, não relatam o desenvolvimento de jogos digitais inspirados no cotidiano das crianças e voltados para a educação ambiental.

\section{Metodologia}

Este trabalho constitui um relato de experiência na escola Aristides Santa Rosa, conforme mencionado anteriormente, que visa aplicar o desenvolvimento de jogos no ensino de conceitos de algoritmos e aprendizado de educação ambiental. Participaram deste trabalho, assistindo as aulas práticas e teóricas, duas turmas do $5^{\circ}$ ano do ensino fundamental, 
VIII Congresso Brasileiro de Informática na Educação (CBIE 2019)

Anais do XXV Workshop de Informática na Escola (WIE 2019)

totalizando 20 alunos com faixa etária entre 9 e 13 anos. Os responsáveis legais pelos alunos, que participaram das atividades aqui descritas, assinaram o Termo de Consentimento Livre e Esclarecido (TCLE).

\subsection{Metodologia das aulas e do desenvolvimento do jogo}

As aulas aconteceram duas vezes por semana no laboratório de informática da escola, por um mês. As aulas iniciais focaram nos conceitos básicos sobre a Computação. Ainda na primeira aula, foram abordados assuntos de LP utilizando, recursos multimídias (slides, imagens, internet) e dinâmicas práticas de construção de algoritmos do dia a dia das crianças: algoritmo para cozinhar um bolo, para escovar os dentes, entre outros. Explicando para os estudantes, de forma lúdica, o que são passos lógicos e como um algoritmo funciona.

Nas aulas seguintes formaram-se grupos de 3 alunos por computador. Neste momento, iniciou-se a construção do jogo. Quando as crianças já estavam reunidas em grupos e inserindo os personagens (lixo, rio, peixes, menino) e densevolvendo a programação, deu-se início ao ensino de temas referentes a preservação do meio ambiente e uso sustentável do rio local. Para isso utilizou-se a construção e os componentes do jogo-base: ao inserir o personagem menino, os alunos foram chamados atenção quanto ao seu papel, no que tange a preservação e uso sustentável da floresta amazônica e seus recursos.

Ao inserir o rio, como pano de fundo, foi discutida a sua importância para as crianças e toda população local. Com a inserção dos peixes, falou-se da flora e fauna amazônica e de sua relevância para a floresta e para as próprias pessoas. Também ressaltou-se como utilizar a flora e fauna de forma sustentável. Com a inserção dos lixos, foram abordadas as consequências negativas desta poluição para o meio ambiente e para o ser humano, além de dar exemplos do descarte correto de resíduos sólidos recicláveis. Sendo assim, as crianças tomaram conhecimento não apenas sobre conceitos de computação, mas aprenderam de maneira lúdica e direcionada sobre assuntos como sustentabilidade e preservação ambiental, temas inerentes à educação ambiental.

Para avaliar se os alunos de fato compreenderam e absorveram os conceitos de algoritmos e educação ambiental, os alunos, primeiramente, seguiram as instruções da professora e construíram o jogo-base e, em um segundo momento, modificaram sua lógica e design, aplicando na prática o que aprenderam nas aulas anteriores. Optou-se por dividir os alunos em grupos e o uso de atividades que envolvessem jogos, para ajudar na construção do aprendizado, com base na teoria do pós-construtivismo, a qual fala que todos podem aprender juntos e que o aprendizado em grupo é muito importante devido ser um ato social [Grossi 1990]. Além disso, [Vygotsky 1989], fala que o jogo é uma forma considerável de desenvolvimento devido abranger todas as tendências evolutivas de maneira condensada.

\subsection{Construção do jogo}

Para as aulas decidiu-se em utilizar o software Scratch pois é uma ferramenta gratuita, disponível no idioma português e desenvolvida para a faixa etária de alunos que participaram deste trabalho. [Rezende and Bispo 2018] em sua pesquisa fala que usar a linguagem Scratch contribui para o aprendizado dos conceitos de algoritmo. 
VIII Congresso Brasileiro de Informática na Educação (CBIE 2019)

Anais do XXV Workshop de Informática na Escola (WIE 2019)

\subsubsection{Descrição do jogo-base}

Visualmente, o jogo é composto por uma imagem de fundo, dois peixes, um menino e alguns sacos de lixo (Figura 1). O menino ensina as instruções do jogo através de caixas de texto. Usou-se algoritmos bem simples, levando em consideração a faixa etária e o nível de conhecimento dos alunos (inferido através de um questionário estruturado antes das aulas).

O objetivo principal do jogo é retirar o lixo que está no rio antes que os peixes encostem nos sacos de lixo. Caso isso aconteça, os peixes desaparecem (morrem). Com um clique com botão direito do mouse em cima do saco de lixo, este é removido do rio. $\mathrm{O}$ jogador vence quando todo lixo for retirado. Os personagens, panos de fundo e os blocos lógicos, usados na construção do jogo, estavam disponíveis no próprio software, mas alguns grupos optaram por imagens retiradas da Internet. A lógica de cada personagem foi criada separadamente, o que ajudou as crianças a saberem de qual personagem era cada bloco de comando desenvolvido.

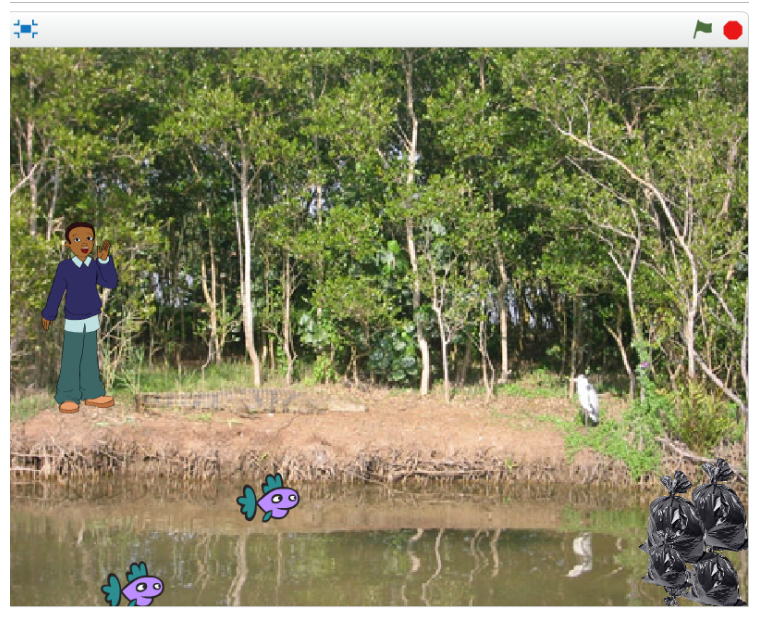

Figura 1. Design visual do jogo-base.

As ações do personagem peixe durante o jogo foram: movimentar-se até a direção do lixo e desaparecer caso encostasse neles. Os blocos de lógica para essas ações estão na (Figura 2).

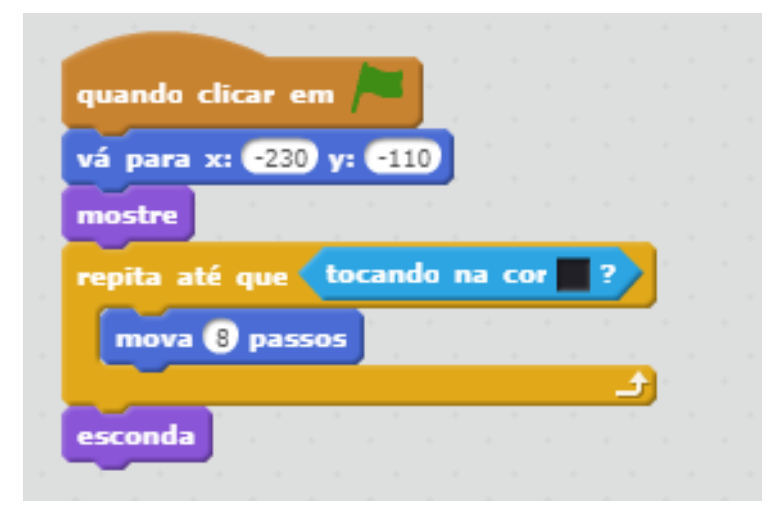

Figura 2. Lógica de programação do personagem peixe. 
VIII Congresso Brasileiro de Informática na Educação (CBIE 2019)

Anais do XXV Workshop de Informática na Escola (WIE 2019)

O bloco laranja especifíca que, quando clicar no botão de início do jogo, o peixe deveria se movimentar e realizar as ações para as quais foi programado. Já o bloco azul indicava a direção que o peixe deveria ir e o lilás (escrito "mostre") era responsável por manter o peixe visível enquanto ele não tocasse no lixo. O bloco de repetição (amarelo) realizava o movimento do peixe, ou seja, mantinha-o nadando repetidamente enquanto ele não tocasse na cor preta que representava o lixo. O bloco azul escuro, também presente no bloco amarelo, era responsável pelo movimento e velocidade do peixe. Por último, o bloco lilás (escrito "esconda") tornava o peixe invisível quando o mesmo encostasse nos sacos de lixo.

A ação do personagem menino era dar instruções para o usuário através de caixas de diálogos. O primeiro bloco (laranja) indicava que, ao clicar no botão de início do jogo, o menino realiza as ações para as quais foi programado. O primeiro bloco (lilás) era responsável por mudar a postura do menino dando a impressão de movimento. O segundo e terceiro blocos diziam respeito às instruções passadas pelo menino ao usuário do jogo e o tempo que essas instruções ficariam disponíveis (Figura 3).

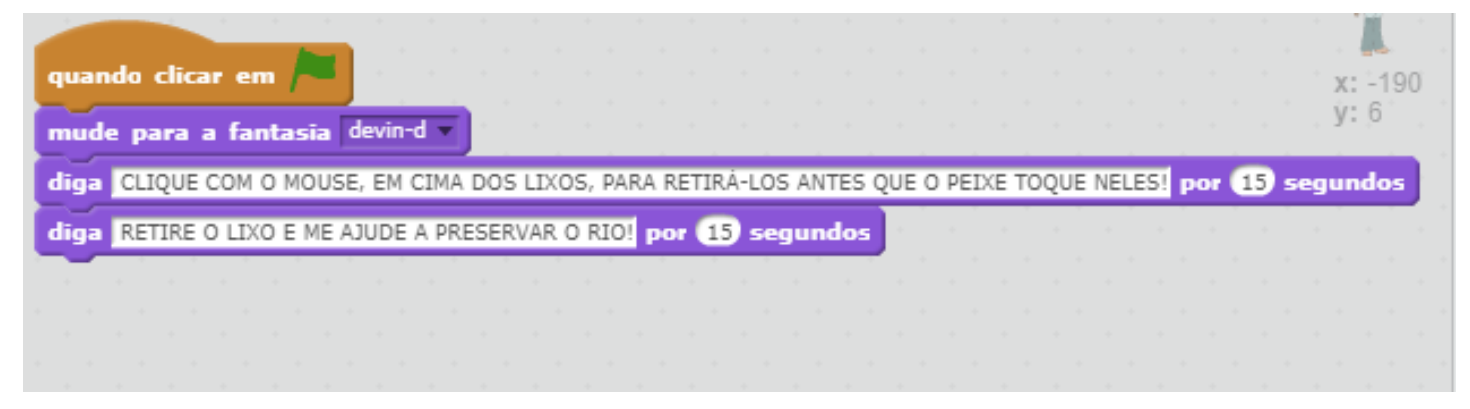

Figura 3. Lógica de programação do personagem menino.

A ação do personagem lixo era desaparecer quando fosse clicado com o botão direito do mouse. O primeiro bloco (laranja) indicava que, quando o botão de início do jogo fosse pressionado, o lixo realizava as ações para as quais foi programado. O bloco lilás (escrito "mostre") era responsável por tornar os sacos de lixo visíveis ao iniciar o jogo. O bloco laranja deveria realizar a ação do bloco seguinte (lilás - escrito o "esconda") no qual, caso os sacos de lixo fossem clicados através do mouse, o lixo desaparecesse (Figura 4).

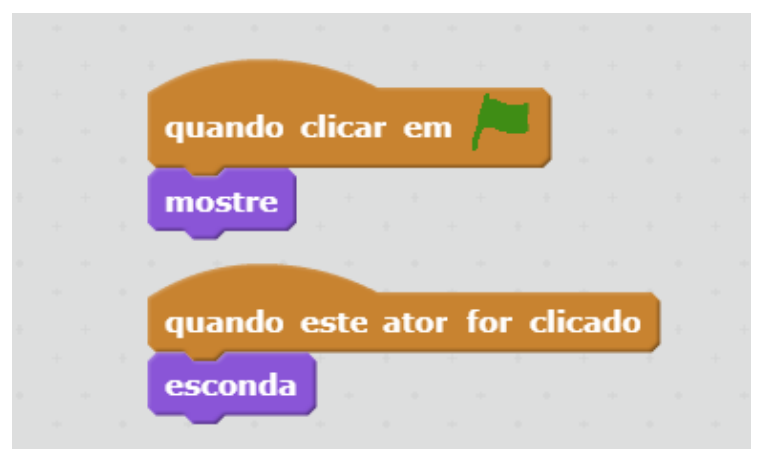

Figura 4. Lógica de programação do personagem lixo. 
VIII Congresso Brasileiro de Informática na Educação (CBIE 2019)

Anais do XXV Workshop de Informática na Escola (WIE 2019)

\section{Avaliação e resultados}

A avaliação dos resultados foi realizada de duas formas: através de dois questionários estruturados, sendo um aplicado antes do início das aulas (teóricas e práticas), o questionário pré-projeto, e outro após o fim das aulas e término da construção do jogo, o questionário pós-projeto. As perguntas contidas nos questionários, eram de caráter de múltipla escolha e resposta aberta. Na (Figura 5) estão destacadas as principais perguntas contidas nos questionários e os resultados das respotas dos alunos, antes e após o final das atividades na escola. A segunda forma de avaliação aconteceu utilizando uma atividade em sala, na qual foi solicitada que os alunos, aplicando os conteúdos de LP e de educação ambiental discutidos, modificassem o design e lógica do jogo-base, ou seja, construíssem jogos diferentes porém aplicando os conceitos vistos durante aS aulas. Esse tipo de atividade, modificar uma programação já existente, é conhecida como remixagem. [MATTAR 2010] afirma que a ideia de remixagem é muito utilizada em projetos no Scratch.

\subsection{Resultado dos questionários estruturados}

\begin{tabular}{|c|c|c|}
\hline Pergunta: & Primeiro questionário: & Segundo questionário: \\
\hline $\begin{array}{l}\text { Qual meio de informação } \\
\text { mais utilizado? }\end{array}$ & $\begin{array}{l}\text { Televisão (75\%) } \\
\text { Internet }(20 \%) \\
\text { Rádio }(5 \%)\end{array}$ & $\mathrm{X}$ \\
\hline $\begin{array}{c}\text { Você já ouviu falar em } \\
\text { algoritmo? Se sim, o que é? }\end{array}$ & Todos responderam que não. & $84 \%$ conseguiu responder. \\
\hline $\begin{array}{l}\text { Você sabe o que é } \\
\text { sustentabilidade? }\end{array}$ & Todos responderam que não. & $35 \%$ conseguiu responder. \\
\hline $\begin{array}{c}\text { Você costuma ir ao rio? } \\
\text { Se sim, com que frequência? }\end{array}$ & $\begin{array}{c}\text { Todos responderam que sim, } \\
\text { frequentemente. }\end{array}$ & $\mathrm{X}$ \\
\hline $\begin{array}{c}\text { Você sabe o que é } \\
\text { preservação ambiental? }\end{array}$ & $\begin{array}{l}75 \% \text { respondeu não saber. } \\
25 \% \text { Respondeu corretamente. }\end{array}$ & $\begin{array}{c}\text { Todos }(100 \%) \text { conseguiram } \\
\text { responder. }\end{array}$ \\
\hline $\begin{array}{l}\text { Você gostaria? } \\
\text { /gostou de aprender a } \\
\text { construir um jogo? }\end{array}$ & $\begin{array}{c}\text { Todos }(100 \%) \text { responderam } \\
\text { que sim. }\end{array}$ & $\begin{array}{c}\text { Todos (100\%) responderam } \\
\text { que sim. }\end{array}$ \\
\hline
\end{tabular}

Figura 5. Resultado dos questionários estruturados.

O primeiro questionário (Figura 5) continha perguntas para obter informações sobre a faixa etária das crianças, o meio de informação utilizado por elas e qual a relação que elas tinham com o meio ambiente. De acordo com o primeiro questionário, $65 \%$ do alunos são do sexo masculino e $70 \%$ estão na faixa etária de oito a dez anos de idade. O meio de informação mais usado pelos alunos é a televisão (75\%), porém $83 \%$ das crianças gostariam de ter mais acesso à Internet. Em relação ao uso do rio que atravessa o município e de seus recursos, $100 \%$ dos alunos responderam que fazem uso do rio cotidianamente. Além disso, $79 \%$ dos alunos falaram que viram lixo tanto no rio, como em suas margens, $100 \%$ das crianças não sabiam o que era sustentabilidade, $75 \%$ não sabiam o que era preservação ambiental e 57\% não sabiam os danos de poluir o rio.

No questionário respondido após as aulas (Figura 5), 100\% das crianças demonstraram saber a respeito das consequências de poluir o rio ao conseguirem responder as perguntas presentes no questionário, a respeito desse tema, como por exemplo:"Você sabe os 
VIII Congresso Brasileiro de Informática na Educação (CBIE 2019)

Anais do XXV Workshop de Informática na Escola (WIE 2019)

danos de poluir o rio?"e sabiam o que é preservação ambiental, pois conseguiram explicar corretamente, com suas próprias palavras, o conceito de preservação do meio ambiente bem como preservá-lo. Trinta e cinco por cento das crianças demonstraram saber a respeito do que é sustentabilidade ao responderem corretamente o que era sustentabilidade, no segundo questionário.

Sobre o conhecimento das crianças a respeito de programação, observou-se o mínimo ou nenhum conhecimento sobre isso por ocasição da aplicação do primeiro questionário e construção do primeiro jogo. Após o fim das aulas, $84 \%$ das crianças responderam satisfatoriamente as perguntas presentes no segundo questionário sobre lógica e algoritmo, bem como externalizaram o interesse em continuar aprendendo a respeito dos assuntos estudados, ao afirmarem querer continuar aprendendo sobre programação e construção de jogos. Inicialmente, $91 \%$ dos alunos responderam não saber o que era um aplicativo (software), porém após as aulas, segundo os dados do questionário, 82\% já tinham adquirido esse conhecimento ao conseguirem responder perguntas que exigiam conhecimento a respeito do que era uma aplicação.

\subsection{Avaliação da atividade de mudança do jogo-base}

Quando os alunos finalizaram a construção do jogo-base em grupo e os conceitos de LP e práticas sustentáveis já tinham sido ensinados, pediu-se aos grupos que mudassem o design e a lógica do jogo desenvolvido. Essa atividade foi realizada sob a supervisão de adultos. Os grupos foram avaliados pelo tipo de mudanças que conseguiram aplicar ao jogo-base: procurou-se avaliar quantos grupos mudaram apenas o design, mantendo a mesma lógica ensinada, e quantos grupos mudaram o design e desenvolveram uma lógica diferente daquela aplicada no jogo-base.

Pode-se afirmar que todos os grupos conseguiram concluir a tarefa de maneira total ou parcial, visto que $45 \%$ dos grupos alterou apenas parte do design, mas aplicou os comandos de programação nos mesmos personagens, enquanto 55\% dos grupos conseguiram mudar o design, aplicar os comandos de lógica em personagens diferentes, adaptando-os ou mudando alguns comandos dentro do algoritmo de cada personagem.

Ressalta-se que todos os grupos mantiveram a preservação do meio ambiente e a sustentabilidade como foco dos novos jogos, aplicando conceitos que aprenderam em sala de aula sobre educação ambiental. A (Figura 6) ilustra o novo design do jogo de um grupo o qual manteve alguns personagens (lixo e peixe) do jogo-base e aplicou os comandos de lógica de maneira diferente para os personagens, além de adicionar um novo personagem, o mergulhador.

No jogo-base o peixe se move em direção ao lixo e o personagem menino dá as instruções. Na (Figura 6) o personagem mergulhador é quem se move e dá as instruções. Portanto, a lógica de programação do mergulhador (Figura 7), apesar de ser baseada nos comandos dos personagens peixe e lixo do jogo-base, difere em alguns aspectos dos personagens peixe e menino pois o mergulhador é programado para mostrar durante todo o jogo informações para o jogador e não apenas por um espaço curto de tempo, como ocorre com o personagem menino. Além disso, ao contrário do peixe que desaparece se encostar no lixo, o mergulhador não desaparece. 
VIII Congresso Brasileiro de Informática na Educação (CBIE 2019)

Anais do XXV Workshop de Informática na Escola (WIE 2019)

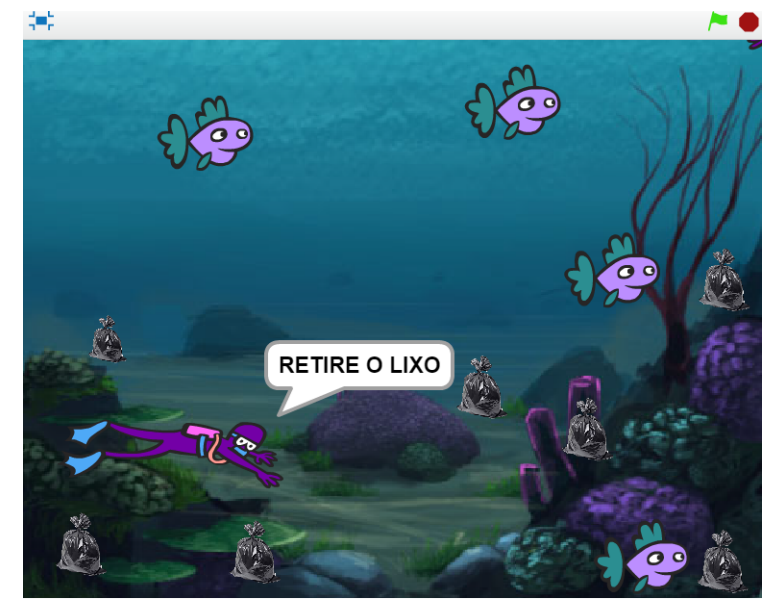

Figura 6. Novo design do jogo desenvolvido por um dos grupos.

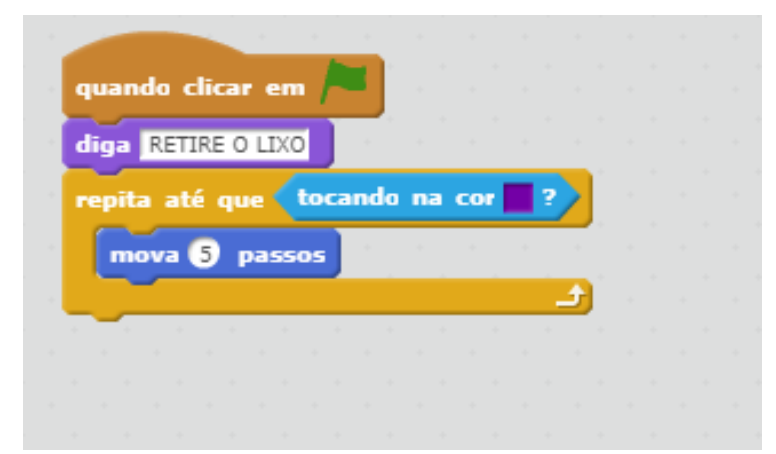

Figura 7. Lógica de programação do personagem mergulhador.

\section{Conclusão}

Os resultados dos questionários monstraram que, apesar de usufruírem da natureza e seus recursos, os alunos não tinham conhecimento sobre preservação ambiental. Após as aulas, com as discussões sobre sustentabilidade e preservação do meio ambiente aliado ao uso do computador para uma atividade direcionada (construção do jogo), eles adquiriram mais conhecimento a respeito da importância de preservar o rio e seus recursos. Através do questionário pré-projeto foi possível identificar que $100 \%$ das crianças não tinham nenhum conhecimento sobre LP o e $91 \%$ não tinham conhecimento a respeito de aplicativos. Já o questionário pós-projeto mostrou que $84 \%$ delas conseguiram absorver conceitos teórico sobre algoritmo, visto que responderam corretamente às perguntas sobre o assunto no questionário.

A atividade em que solicitou-se aos grupos de alunos que alterassem a lógica e design do jogo-base, mostrou que a maioria dos alunos (55\%) conseguiu aplicar os comandos de lógica ensinados através da construção do jogo, o que demonstra que crianças conseguem aprender conceitos de programação, através de atividades supervisionadas e adaptadas para a idade deles.

Portanto, percebe-se que o uso de jogos educacionais na escola e as NTDICs são atraentes aos alunos e podem ser utilizados como uma ferramenta de auxílio no processo de ensino e aprendizagem de computação e outros assuntos pertinentes (sustentabilidade e preservação ambiental, por exemplo), proporcionando um ambiente bastante interativo. 
VIII Congresso Brasileiro de Informática na Educação (CBIE 2019)

Anais do XXV Workshop de Informática na Escola (WIE 2019)

Como trabalhos futuros indica-se a continuação das aulas de ensino de programação na escola, além de usar os jogos na promoção de práticas sustentáveis e preservação do meio ambiente nas escolas da cidade, visto que é uma região tipicamente amazônica e percebe-se a necessidade de despertar na população, ainda na infância, a consciência e a responsabilidade socioambiental.

\section{Referências}

Alves, J. N., Almeida, A. M. F., Vieira, M. D., Carvalho, A. R., and Leite, M. A. G. L. Ifquimical: uma proposta de mediação no processo ensino-aprendizagem de quimica. In Anais do XXIX Simpósio Brasileiro de Informática na Educação.

Cruz, D. M., Albuquerque, R. M., and Azevedo, V. B. Criar e jogar seu próprio jogo: a produção de games na escola. In Anais do IV Computer on The Beach.

Farias, C., Azevedo, F. P., and Dias, J. L. J. (2018). Uma abordagem gamificada para o ensino de lógica de programação: relato de experiência. In XXVI Workshop sobre Educação em Computação, Natal.

Garlet, D., Bigolin, N., and Silveira, S. (2016). Uma proposta para o ensino de programação de computadores na educação básica. Departamento de Tecnologia da Informação, Universidade Federal de Santa Maria, RS.

Grossi, E. (1990). Didática da alfabetização. Paz e Terra.

Guerra, F. V. A., Santos, J. A. M., Guerrero, D. D. S., and Figueiredo, J. C. A. (2018). zreader: a mobile game suite for improving children's reading skills and behavior. In Anais do XXIX Simpósio Brasileiro de Informática na Educação.

MATTAR, J. (2010). Games em Educação: como os nativos digitais aprendem. Pearson Prentice Hall.

Mesquita, O., Aranha, E. H. S., and Silva, T. R. (2018). Uma abordagem para o desenvolvimento de jogos digitais educativos no ensino básico. In Anais do XXIX Simpósio Brasileiro de Informática na Educação.

Mittermeir, R. (2013). Algorithmics for preschoolers-a contradiction? Creative Education, 4(09):557.

Pires, F. G. S., Michel, F., Bernardo, J. R. S., Ferreira, R. M., Freitas, R., and Neto, C. S. S. (2018). O livro do conhecimento: um jogo de aventura para exercitar a ortografia. In Anais do XXIX Simpósio Brasileiro de Informática na Educação.

Rezende, C. and Bispo, E. (2018). Comparison between the use of pseudocode and visual programming in programming teaching: An evaluation from scratch tool. In 2018 13th Iberian Conference on Information Systems and Technologies (CISTI), pages 15. IEEE.

Vygotsky, L. (1989). O papel do brinquedo no desenvolvimento. A formação social da mente, 4:105-118.

Williams, C., Alafghani, E., Daley, A., Gregory, K., and Rydzewski, M. (2015). Teaching programming concepts to elementary students. In Frontiers in Education Conference (FIE), 2015 IEEE, pages 1-9. IEEE. 